\title{
Orthostatic hypotension and nicotine sensitivity in a case of multiple system atrophy
}

\author{
J. G. GRAHAM AND D. R. OPPENHEIMER \\ From the Department of Neurology, Cardiff Royal Infirmary, and the Department of Neuropathology, \\ the Radcliffe Infirmary, Oxford
}

Shy and Drager (1960), on the basis of some 40 published case reports, described a clinical syndrome to which their names have subsequently been attached. The complete syndrome includes orthostatic hypotension, anhidrosis, urinary and faecal incontinence, sexual impotence, Parkinsonian signs, external ocular palsies, amyotrophy, and iris atrophy. A detailed post-mortem examination of one of their cases showed neuronal degeneration at many sites, including the intermediolateral columns of the spinal cord. They did not comment on the relation of this finding to the autonomic features of their patient's disorder.

In 1965, Fichefet, Sternon, Franken, Demanet, and Vanderhaeghen described a case presenting with orthostatic hypotension, with subsequent development of Parkinsonism. The pathology was that of idiopathic paralysis agitans, with Lewy-type cytoplasmic inclusions and loss of pigmented nerve cells. In addition, the authors observed some cell loss in the anterior and lateral horns of the spinal cord.

In 1966, Johnson, Lee, Oppenheimer, and Spalding described the clinical, physiological, and pathological findings in two cases of orthostatic hypotension. In the first of these, the only associated disturbances were sexual impotence and loss of sweating. Lewy-type inclusions were found in the pigmented nuclei and elsewhere, but there was no detectable loss of pigmented cells. Cell loss in the intermediolateral columns was estimated at nearly $90 \%$. In the second case, the autonomic disorder was followed, after a few years, by a progressive disorder of motor and cerebellar function. The lesions were those of olivo-ponto-cerebellar atrophy; in addition, there was cell loss, estimated at about $75 \%$, in the intermediolateral columns. Since then, there have been four reports on cases that have gone to necropsy - that of Nick, Contamin, Escourolle, Guillard, and Marcantoni (1967) and the two cases of Schwarz (1967) - all of which showed neuronal degeneration at various sites, including the inter- mediolateral columns; and the case of Martin, Travis, and van den Noort (1968), which showed pro relevant CNS pathology.

The case reported here showed certain features of the Shy-Drager syndrome, including orthostafic hypotension, impotence, and incontinence. THe patient also suffered from a cerebellar type of atax which was temporarily made very much worse by smoking a cigarette. This type of sensitivity to nicotine has been reported by Spillane (1955็ iin patients with spino-cerebellar disease, but त्रुgi, hitherto, in association with the Shy-Drager 艿y+drome. The object of this paper is to prøicte evidence that (1) in this, as in other cases afthe Shy-Drager syndrome, the basic disease is a prigaaty atrophy of a selection of neurones in the \& (2) the features of sympathetic failure, including orthostatic hypotension, are attributable to cel[itoss in the intermediolateral columns; (3) nicotifie sensitivity is associated with cerebellar system disorders, which are present in some cases of the Shy-Drager syndrome. There does not appear to ge a direct connection between nicotine sensitivity agd autonomic failure.

\section{CASE REPORT}

A 60-year-old unmarried male street photographer $\underset{\text { wats }}{\ulcorner}$ admitted to hospital in April 1964 complaining of unsteadiness of gait, which had developed over the pæist four months. For 18 months, he had had urinary hesijancy, dribbling, and nocturnal incontinence, and sextel impotence. He had noticed that cigarette smoking made the unsteadiness very much worse, and made his legs feel 'wooden'. A year before, in a cinema, he had gome to the back of the auditorium for a smoke. He remembered lighting a cigarette, and the next memory wo s of regaining his senses in the manager's office, feeling unwell, but rapidly returning to normal. It is not knon whether he struck his head in falling. Witnesses made $\overline{\overline{\mathrm{n \rho}}}$ mention of convulsive movements.

Apart from three attacks of chest pain at rest, earch lasting a quarter of an hour, there was no relevant p\&st 
medical history. His mother died aged 35, of unknown causes, and his father aged 56, of Bright's disease. His

- family consisted of one half-brother and one aunt, both healthy.

On admission, he was unkempt and slovenly, but of high intelligence and lively wit. The pulse was regular at $100 / \mathrm{min}$, and the blood pressure (taken lying down), was $170 / 100 \mathrm{~mm} \mathrm{Hg}$. The bladder was palpably distended, without distress. The gait was broad-based and ataxic, and walking heel to toe was impossible. Speech was slurred, and there were permanent small collections of saliva at the angles of the mouth. There were no cranial nerve lesions, and no nystagmus. In the upper limbs tone, power and co-ordination were normal; the reflexes were symmetrically hyperactive, with brisk finger jerks, but negative Hoffmann's and Wartenberg's signs. The lower limbs, especially the left, were ataxic, with slight proximal weakness. The right plantar response was absent, the left flexor. All modalities of sensation were normal.

Investigations included a full blood count, blood urea, serum cholesterol, serum proteins and electrophoresis, midstream urine analysis, liver function tests, blood Wassermann reaction, radiography of chest (with screening), abdomen, skull, dorsal and lumbar spine, electrocardiography and electroencephalography (EEG). The only abnormalities were an ESR of $38 \mathrm{~mm}$ in $1 \mathrm{hr}$, a trace of albuminuria with sterile culture, and slightly raised serum $\alpha$ and $\beta$ globulin concentrations. A diagnosis of spinocerebellar degeneration was made, and vitamins $B_{1}$ and $B_{12}$ prescribed as a placebo.

He was not seen again until July 1966, when he was readmitted, all the earlier symptoms and signs having worsened. His speech was now barely intelligible, and became quite unintelligible after smoking a cigarette. He was unable to walk without assistance and had to wear a portable urinal. He was more unkempt than ever, but his intellect was quite unimpaired and contrasted even more sharply with his physical state. There was no nystagmus. He had gross ataxia with slight proximal weakness in all four limbs; reflexes remained symmetrically hyperactive, abdominal reflexes were absent, and plantar responses were equivocal. There was impair- ment of vibration sense in both feet, but no other sensory disturbance. He had bilateral dependent oedema.

In addition he complained of about six attacks of abrupt loss of consciousness, all of which occurred on rising out of a chair, usually resulting in his falling back into the chair, and once to the floor. Observers had told him that unconsciousness lasted only a few seconds, during which he was pale, with open glazed eyes. He did not become rigid or convulse. His blood pressure was recorded lying and standing over a period of days, and was persistently lower on standing, often by as much as 50 to $60 \mathrm{~mm} \mathrm{Hg}$ systolic.

Investigations at this time included an ESR of 28 millimetres, bilateral high tone deafness, worse on the right, a normal EEG, normal cerebrospinal fluid, normal chest and skull radiographs, and an air encephalogram showing normal posterior fossa anatomy but slight ventricular dilatation and a slight excess of air in the cerebral cortical sulci.

A histamine infusion test showed that he was almost achlorhydric (acid output $0 \cdot 19 \mathrm{~m}$-equiv/hr), so that an insulin-induced acid output became irrelevant as a test of autonomic function. Continuous recordings of his blood pressure were made with an intra-arterial cannula connected through a pressure transducer to a Devices recorder, the patient being strapped to a tilting table. The response to tilting is shown in Figure 1. The patient's response to the Valsalva manoeuvre is contrasted with a normal response in Figure 2. In view of the effects of tobacco on his cerebellar disorder, these tests were repeated after smoking two cigarettes, but, apart from a slight general rise in blood pressure, no effect was noted. There was a sharp rise in blood pressure following an intravenous infusion of noradrenaline $(8 \mu \mathrm{g} / \mathrm{ml}$.). demonstrating that his vessels were capable of constriction. No quantitative assessment of the response was made. There was no response to a sudden loud noise nor during the performance of mental arithmetic. Sweat tests were not performed.

He was transferred to another hospital, where after developing urinary and chest infections he died in December 1966.

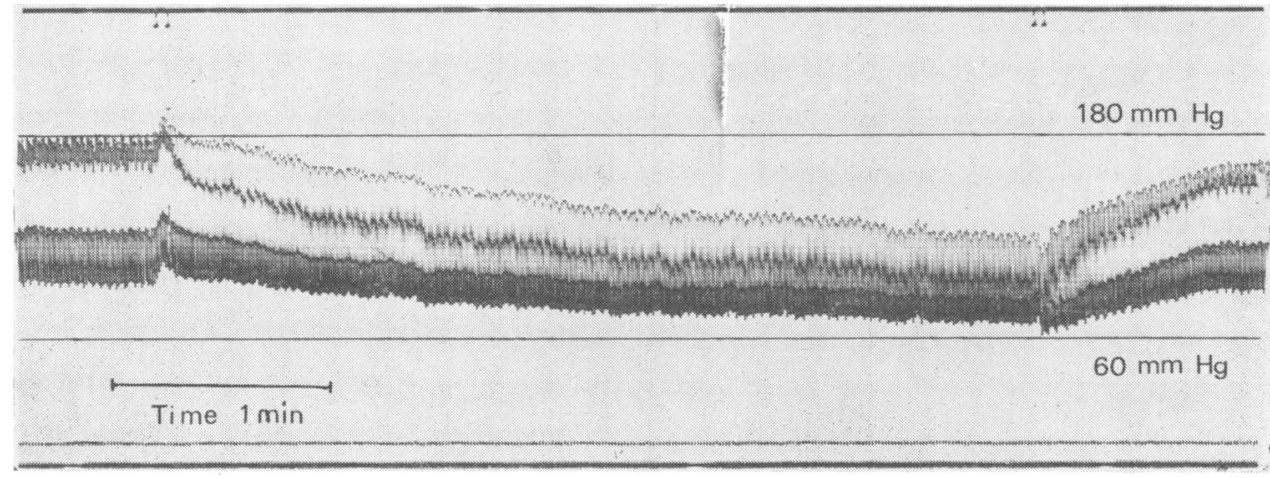

FIG. 1. The effect of tilting on the patient's blood pressure. The double event marks on the upper channel indicate the beginning and end of the period of feet-down tilt. The normal response is a rise in blood pressure. 


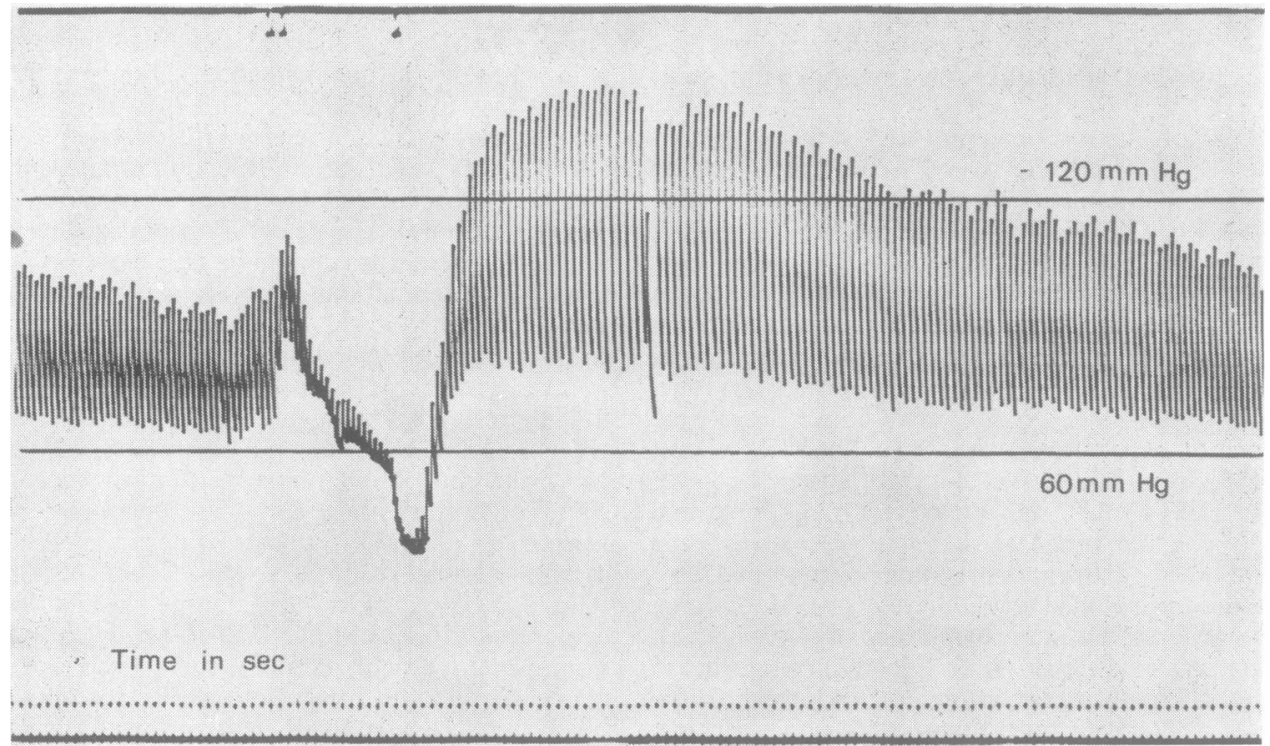

FIG. $2 a$.

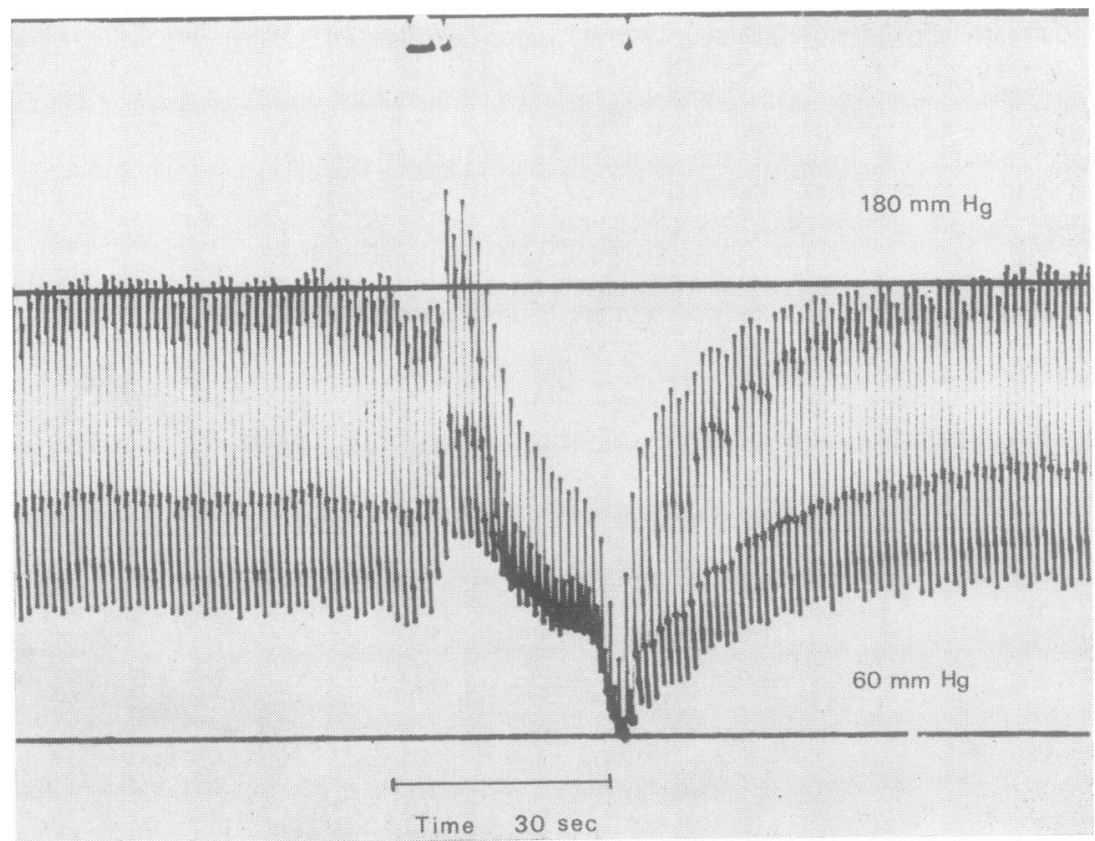

FIG. $2 b$.

FIG. 2. Blood pressure response to the Valsalva manoeuvre. Normal response in upper recording. Note the failure of 'rebound' in the patient's record. 


\section{PATHOLOGY}

Necropsy was carried out by Dr. K. M. Laurence, who very kindly supplied us with the brain, spinal cord, and other tissues. The gross findings were of purulent tracheobronchitis, bilateral bronchopneumonia, old pleurisy, old apical tuberculosis, and atheroma of the aorta and other main arteries. The brain $(1,370 \mathrm{~g}$; hind brain alone $150 \mathrm{~g}$ ) was externally unremarkable, apart from an old traumatic scar, $2 \mathrm{~cm}$ in diameter, in the right orbital cortex. The cerebral vessels were healthy. On section there were no naked-eye abnormalities in the brain, spinal cord or nerve roots.

HISTOLOGICAL FINDINGS 1. Cerebral hemispheres The only striking abnormality was a symmetrical heavy cell loss, with astrocytic gliosis, in the putamen, affecting particularly the dorsal and lateral parts. The ventral parts of the putamen, and the caudate nuclei, appeared normal. There was a corresponding loss of myelin, and gliosis without cell loss, in the globus pallidus on both sides. Cortex, hippocampus, thalamus and amygdaloid nuclei appeared normal; the hypothalamus, examined at $1 \mathrm{~mm}$ intervals, was unremarkable.

2. Brain-stem and cerebellum There was no gross atrophy of the pons, but there was loss of cells and of transverse fibres in a narrow strip over the ventral surface of the pons, and astrocytic gliosis of the remaining pontine nuclei. Symmetrical cell loss and gliosis were seen in the lateral thirds of the substantia nigra, the dorsal laminae of the inferior olives, the medial vestibular nuclei, the lateral reticular nuclei of the lower medulla, and the dorsal vagal nuclei (Fig. 3). Cranial motor nuclei appeared intact. In the cerebellum there was a severe loss of Purkinje cells in all parts of the vermis, accompanied by abundant torpedo formations, Bergmann gliosis, and fibrillary gliosis of the white matter. Basket and granule cells were preserved. Purkinje cell loss was patchy and not very severe in the cerebellar hemispheres. There was

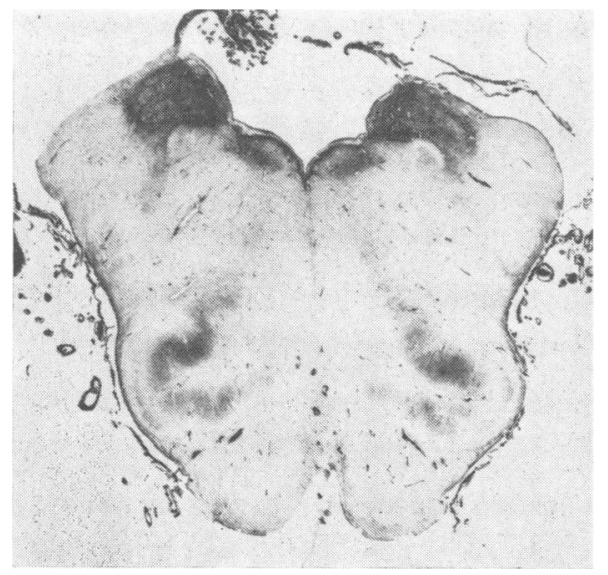

FIG. 3. Upper medulla, showing gliosis in the medial vestibular and dorsal vagal nuclei. Holzer stain for fibroglia. no obvious cell loss in the dentate and roof nuclei, but these nuclei showed active microgliosis, and a diffuse stippling with Sudanophil lipid. The central white matter showed astrocytic gliosis and slight Sudanophil stippling. There was no demonstrable loss of fibres in the superior cerebellar peduncles.

3. Spinal cord There was a mild degeneration in both crossed and uncrossed pyramidal tracts, more marked in the lower segments, and not detectable in the medullary pyramids. The spinocerebellar tracts appeared intact. There was no obvious loss of motor cells in the anterior horns, but many of them were small and pyknotic. The cells of Clarke's columns showed an unusual degree of loading with lipochrome. In the thoracic segments there was a very severe loss of cells in the intermediolateral columns. Cell counts were carried out on six $20 \mu$ sections from each thoracic segment (except T11, which was damaged post mortem) and the first lumbar segment. The figures (Table I) were compared with pooled control material, as in Johnson et al. (1966), and with the cases described there. They showed an overall loss of about $80 \%$ of these cells. The loss was much more severe on the right than on the left.

\section{TABLE $I^{1}$}

MEAN COUNTS OF NUMBER OF CELLS IN EACH LATERAL HORN IN $20 \mu$ SECTIONS, WITH STANDARD ERRORS*

\begin{tabular}{ccccc}
\hline Level & $\begin{array}{c}\text { Pooled } \\
\text { controls }\end{array}$ & $\begin{array}{c}\text { Johnson } \\
\text { et al. } \\
\text { (case 1) }\end{array}$ & $\begin{array}{c}\text { Johnson } \\
\text { et al. } \\
\text { (case 2) }\end{array}$ & $\begin{array}{c}\text { Present } \\
\text { case }\end{array}$ \\
\hline T1-4 & $\begin{array}{c}15 \cdot 8 \pm 1 \cdot 0 \\
(48)\end{array}$ & $\begin{array}{c}1 \cdot 3 \pm 0 \cdot 3 \\
(36)\end{array}$ & $\begin{array}{c}4 \cdot 3 \pm 0.5 \\
(36)\end{array}$ & $\begin{array}{c}4 \cdot 2 \pm 0 \cdot 6 \\
(48)\end{array}$ \\
T5-8 & $\begin{array}{c}9.2 \pm 0.7 \\
(48)\end{array}$ & $\begin{array}{c}1 \cdot 0 \pm 0 \cdot 2 \\
(36)\end{array}$ & $\begin{array}{c}1.9 \pm 0.2 \\
(48)\end{array}$ & $\begin{array}{c}1.3 \pm 0.2 \\
(48)\end{array}$ \\
T9-12 & $\begin{array}{c}9.5 \pm 0.7 \\
(48)\end{array}$ & $\begin{array}{c}2 \cdot 0 \pm 0.3 \\
(36)\end{array}$ & $\begin{array}{c}2 \cdot 7 \pm 0.3 \\
(48)\end{array}$ & $\begin{array}{c}1.3 \pm 0.2 \\
(48)\end{array}$ \\
\hline
\end{tabular}

*Figures in brackets show the number of counts made at each level. †T9, T10, T12, and L1.

4. Peripheral nervous system There were no detectable changes in the right vagus nerve. Sections of various sympathetic ganglia showed loss of fibres in some of the nerve bundles, but no loss of, or morphological changes in, ganglion cells (Fig. 4). Samples of tongue and neck muscles showed no sign of denervation.

In summary, the pathological findings were of selective neuronal degeneration at multiple sites in the central nervous system. Since no changes were found in the hypothalamus or in peripheral autonomic ganglia, it is reasonable to ascribe the patient's autonomic disorder to the observed loss of preganglionic autonomic cells.

${ }^{1}$ Schwarz (1967) has expressed doubt as to the possibility of making significant evaluations of cell loss by counting methods. Variations in cell density certainly exist from level to level and from section to section. The standard errors, shown above, reflect this variation. We are satisfied that the figures obtained in these three cases show a devastating loss of intermediolateral cells. Loss of functioning cells is probably still greater, since many shrunken, pyknotic cells were included in the counts. 


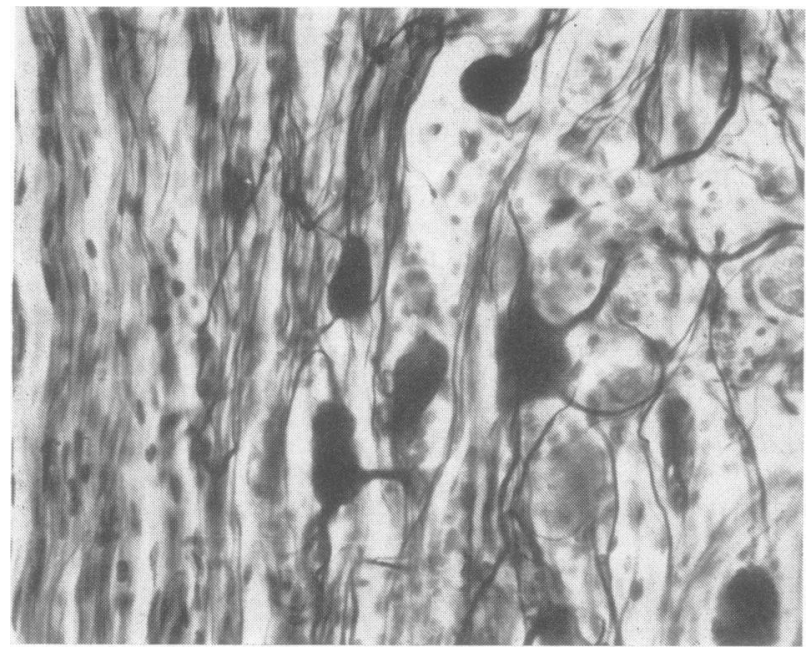

FIG. 4. Thoracic sympathetic ganglion, showing normal ganglion cells. There is some loss of fibres in the bundle on the left. Frozen: Bielschowsky, modified Schofield, $\times 190$.

\section{DISCUSSION}

We know of eight previously reported cases of so-called idiopathic orthostatic hypotension in which a neuropathological examination has been made. A report has recently been published by Martin et al. (1968) on a man aged 59 with orthostatic hypotension, urinary incontinence, laryngeal and external ocular palsies, unilateral hypoalgesia, and spastic legs. The authors were unable to demonstrate any significant lesions in the central or peripheral nervous systems, and are reluctant to believe that anyone else has succeeded in doing so. The remaining seven consist of case 2 of Shy and Drager (1960); the case of Fichefet et al. (1965); cases 1 and 2 of Johnson et al. (1966); the case of Nick et al. (1967); cases 1 and 2 of Schwarz (1967). Intermediolateral column degeneration of some degree has been noted in all these; apart from this, the cases appear to fall into two groups.

In the first group are the case of Fichefet $e t$ al. (1965) and case 1 of Johnson et al. (1966), in both of which there were numerous Lewy-type inclusion bodies in pigmented nuclei and elsewhere. In the former, clinical Parkinsonism developed before death, and there was marked cell loss in the pigmented nuclei. In the latter, Parkinsonism did not develop, and no pigmented cell loss was seen. Neither case showed cell loss in the basal ganglia or in the cerebellar system; and neither case can properly be regarded as an example of the ShyDrager syndrome.

The remaining five cases, and the case reported here, form the second group. The main clinical and pathological features of these are shown in Table II. The similarities are obvious, and it would be unreasonable to attach different diagnostic labels to these cases-for instance, to label four of then 'olivo-ponto-cerebellar atrophy' (OPCA) and the् other two 'striato-nigral degeneration' (Adams;:van Bogaert, and van der Eecken, 1964; Jellingerti and Danielcyzk, 1968). The disadvantages of thiso type of labelling are apparent from the fact the Adams et al. (1964) diagnosed one of their cases ${ }^{2} S_{T}$ 'striato-nigral degeneration and olivo-ponto-ceseo bellar degeneration'.

Welte (1939), in a review of the pathology OPCA, clearly pointed out that the lesions anreported cases were commonly widespread, and viso frequently, but not always, included the striatum and pigmented nuclei. He commented 'These manifold combinations [of lesions] argue for a close relationship between all types and sub-types of̂ system atrophies of the central nervous system'. Byoّ this he presumably meant that these conditions shared some common aetiological factor. We would make the same point in a different way. There is a group of progressive neurological conditions, most often arising during middle life, with symptoms anథ signs of lesions affecting several central nervous structures, more or less symmetrically. These cases are usually sporadic, but sometimes familial. The pathological findings are of cell loss and gliosis in selection of well-defined structures (including botig anatomical 'nuclei' such as the putamen, and extensive cellular layers, such as the Purkinje cells of the cerebellum). In different cases, differen? selections of structures are affected. Some com binations of lesions are commoner than others thus, familiar names, such as OPCA, have comes into use. Nevertheless combinations are encoun N tered which do not correspond with any familian 
TABLE II

MAIN CLINICAL FEATURES OF SIX CASES OF IDIOPATHIC ORTHOSTATIC HYPOTENSION, WITH PRINCIPAL SITES OF HISTOLOGICALLY PROVED CELL LOSS

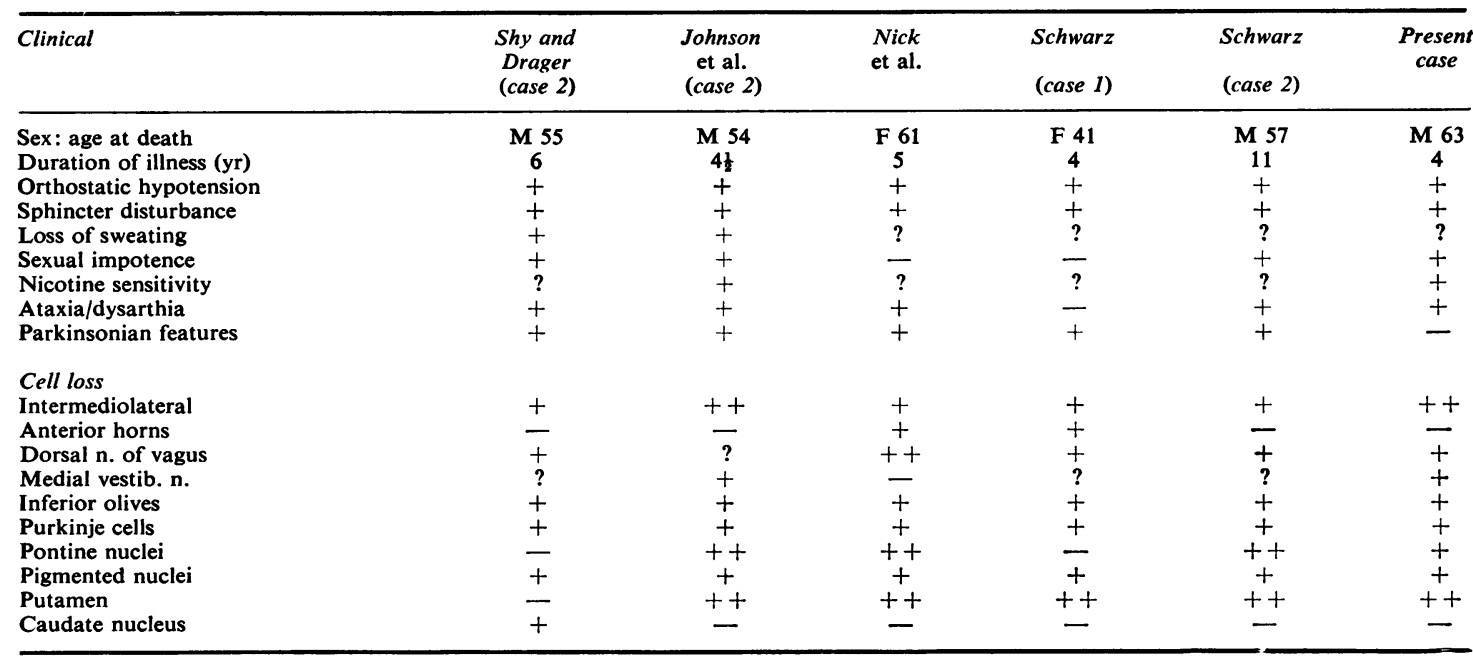

Reports of 'slight cell loss', or morphological changes in cells, have been ignored.

syndrome. In such cases, unnecessary confusion is caused by inventing new names, of the type 'pallidosubthalamico-vestibular atrophy', for unusual syndromes.

Consideration of the familial multisystem degenerations provides a further powerful argument against splitting this group of diseases into so-called entities, since there may be wide variation in the clinical and pathological patterns within a single family (Schut and Haymaker, 1951). In such a case one may only suppose that multiple factors determine the age of clinical manifestation, the selection of systems involved and the order in which they become affected. The same is probably true of sporadic cases.

What is needed is a general term to cover this collection of overlapping progressive presenile multisystem degenerations. As the causes of this group of conditions are still unknown, such a general term would merely be a temporary practical convenience. Theoretically, no doubt, it should cover motor neurone disease - a condition in which the lesions are often widespread, and not confined to motor cells and pyramidal tracts; but for practical reasons one would not wish to do away with the special designation for this condition. What we wish to avoid is the multiplication of names for 'disease entities' which in fact are merely the expressions of neuronal atrophy in a variety of overlapping combinations. We therefore propose to use the term multiple system atrophy to cover the whole group.
Among the structures at risk in this disease we must include the preganglionic cells of the autonomic system. These may be attacked apparently in isolation as in case 1 of Johnson et al. (1966), or in combination with other structures, as in the other cases under discussion. In the latter, it is justifiable to speak of the Shy-Drager syndrome; but it is quite unjustifiable to regard this disorder, in which the autonomic system is affected along with others, as a separate disease entity.

The problem of aetiology in those cases with orthostatic hypotension is the same as in other varieties of multiple system atrophy. We know of no extrinsic exciting cause, and there is at present no evidence of a specific enzyme deficiency. On the genetic side, there is a close parallel with OPCA. Most of the reported cases are sporadic, but some are familial. Lewis (1964) described a family of which at least four members suffered from a slowly progressive disease, with onset in early middle life, characterized by some or all of the following: orthostatic hypotension, amyotrophy, ataxia, rigidity and tremor, and sphincter disturbances. These cases differ from the group which we have been discussing mainly in their relatively benign clinical $c$ urse. Lewis's four patients were alive, and not totally disabled, 17, 39, 19, and 8 years respectively after the onset of symptoms.

Nicotine sensitivity was a striking feature in the case here described. Spillane (1955) described three cases of spinocerebellar degeneration and one of 
multiple sclerosis, all of whom showed sharp temporary deterioration after cigarette smoking. He established that this was due to nicotine itself. Orthostatic hypotension was not looked for, and the histories did not suggest it. Reference to the clinical notes of case 2 of Johnson et al. (1966), made by Dr. J. D. Spillane some years before the patient came under study by Johnson and co-workers, revealed that he had had striking nicotine sensitivity and had stopped smoking as a result. We have recently studied a further patient, kindly referred by Dr. Harold Edwards, who had a degenerative cerebellar syndrome with marked orthostatic hypotension, and who complained of nicotine sensitivity, a complaint amply confirmed by objective tests before and after smoking. Although anhidrosis was demonstrated she was unwilling to submit to further tests of autonomic function. The nicotine effect is not mentioned in Lewis's (1964) report of the familial cases, nor in the papers of Shy and Drager (1960) and Schwarz (1967). Tripodi (1932) described a case of orthostatic hypotension with 'staggering' in a heavy smoker, and ascribed the condition to cigarette smoking, although insufficient detail is provided to assess the justification for doing so.

In our case cigarette smoking had no effect on the tests of vasomotor function. On theoretical grounds, the dosage of nicotine obtained from a cigarette would, if anything, be expected to raise the blood pressure slightly. Moreover it is clear from the histories of the affected patients that it is the cerebellar component of their symptomatology which is affected. We cannot therefore relate nicotine sensitivity to the autonomic component of multiple system atrophy. We can only observe that two uncommon features of this range of disorders, nicotine sensitivity and orthostatic hypotension, have occurred together in two out of the three cases confirmed by necropsy in the British literature, and a fourth case mentioned above also seems to show this association.

\section{SUMMARY}

A 60-year-old man developed a progressive neurological disorder with the following features: cerebellar ataxia, which was exacerbated by smoking, orthostatic hypotension, sexual impotence, and urinary incontinence. At necropsy, he showed neuronal degeneration at multiple sites, including the intermediolateral columns, where the deficiency was estimated at about $80 \%$.

Comparing this case with previously reported cases of $(a)$ the Shy-Drager syndrome and (b) nicotine sensitivity, the authors conclude that:

1. This and other cases of the Shy-Drager syndrome are examples of a group of presenif neuronal degenerations, of which olivo-ponto cerebellar atrophy is one of the better-known varietie? The disease affects different selections of sites if different patients. The intermediolateral columns are among the sites at risk.

2. In such cases autonomic failure is attributab to the degeneration of the autonomic efferent celp which has been demonstrated in the intermedio? lateral columns.

3. Nicotine sensitivity is an occasional feature of cases with cerebellar system degeneration. It cannơ be regarded as part of the autonomic disturbance but its clinical association with this disturbance recorded.

As a general term to cover the many varieties of this disease, the authors suggest 'multiple systery' atrophy'. The term 'Shy-Drager syndrome' is. justified in describing those cases of multiple systerwo atrophy with orthostatic hypotension.

We are grateful to Dr. J. D. Spillane for permission t? publish this case and for his observations on case 2 of Johnson et al., to Dr. Harold Edwards for referring the further case mentioned, to Dr. Sam Galloon for assista. in the autonomic tests, to Dr. John Spalding for क्रis helpful criticisms, to Mr. Ronald Beesley for the hiftological preparations, and to Mr. Ralph Marshall forqhe् illustrations.

\section{REFERENCES}

Adams, R. D., van Bogaert, L., and van der Eecken, H. (1964) Striato-nigral degeneration. J. Neuropath. exp. Neurol.른 23 584-608.

Fichefet, J. P., Sternon, J. E., Franken, L., Demanet, J. C., arf@ Vanderhaeghen, J. J. Etude anatomo-clinique d'un cas d'hypq tension orthostatique 'idiopathique'. Considérations pathø géniques. Acta cardiol. (Brux.), 20, 332-348.

Jellinger, K., and Danielczyk, W. (1968). Striato-nigral degeneratio Acta neuropath. (Berl.), 10, 242-257.

Johnson, R. H., Lee, G. de J., Oppenheimer, D. R., and Spaldin J. M. K. (1966). Autonomic failure with orthostatic hypळ tension due to intermediolateral column degeneration. $\AA$ report of two cases with autopsies. Quart. J. Med., 35, 276-29:

Lewis, P. (1964). Familial orthostatic hypotension. Brain, 87, 719-72\&

Martin, J. B., Travis, R. H., and van den Noort, S. (1968). CentralPy mediated orthostatic hypotension. Arch. Neurol. (Chic.), 1థ 163-173.

Nick. J., Contamin, F., Escourolle, R., Guillard, A., and Marcanton'J. P. (1967). Hypotension orthostatique idiopathique ave्c syndrome neurologique complexe à prédominance exträ pyramidale. Etude anatomo-clinique d'un cas. Rev. Neuro? 116, 213-227.

Schut, J. W., and Haymaker, W. (1951). Hereditary ataxia: a path logic study of five cases of common ancestry. J. Neuropath clin. Neurol., 1, 183-213.

Schwarz, G. A. (1967). The orthostatic hypotension syndrome Shy-Drager. A clinicopathologic report. Arch. Neurol. (Chic. 5 16, 123-139.

Shy, G. M., and Drager, G. A. (1960). A neurological syndrome associated with orthostatic hypotension. A clinical-pathologic study. Arch. Neurol., 2, 511-527.

Spillane, J. D. (1955). The effect of nicotine on spinocerebellar ataxis Brit. med $J ., 2,1345-1351$.

Tripodi, M. (1932). L'ipotensione arteriosa ortostatica. Policlinico Sez. prat., 39, 797-801.

Welte, E. (1939). Die Atrophie des Systems des Brückenfusses undu der unteren Oliven. Arch. Psvchiat. Nervenkr, 109, 649-698. 